\title{
(A,B,C) Triplet of Infrared OH Bands of Zeolitic H-Complexes
}

\author{
A. G. Pelmenschikov, ${ }^{,+, \neq}$J. H. M. C. van Wolput, ${ }^{8}$ J. Jänchen, ${ }^{8}$ and R. A. van Santen \\ Schuit Institute of Catalysis, University of Technology, P.O. Box 513, 5600 MB Eindhoven, \\ The Netherlands, and Institute of Catalysis, Prosp. Lavrentieva 5, 630090 Novosibirsk, Russia
}

Received: April 29, 1994; In Final Form: October 4, $1994^{\otimes}$

\begin{abstract}
The phenomenon of the (A,B,C) triplet of infrared $\mathrm{OH}$ bands at $\sim 2800, \sim 2400$ and $\sim 1700 \mathrm{~cm}^{-1}$, wellknown for strong $\mathrm{X}-\mathrm{OH}=\mathrm{Y}$ molecular $\mathrm{H}$-complexes in solutions, liquids, and solids, is studied for the first time for surface $\mathrm{H}$-complexes using $\mathrm{CD}_{3} \mathrm{CN}$ and $\mathrm{CCl}_{3} \mathrm{CN}$ adsorption on deuterated $\mathrm{H}$-ZSM5 and H-FeSil zeolites. A direct experimental proof is given that the minimum between the $\mathrm{A}$ and $\mathrm{B}$ bands of $\mathrm{D}$-complexes occurs at nearly exactly the $2 \delta(\mathrm{OD})$ in-plane bending overtone frequency of the perturbed OD group. This verifies the resonance theory of the $(A, B)$ doublet by Claydon and Sheppard. In reference to zeolites this means that the $\sim 2800$ and $\sim 2400 \mathrm{~cm}^{-1} \mathrm{OH}$ bands recently found in adsorption of many basic molecules on zeolitic $\mathrm{OH}$ groups are actually pseudobands, caused by the subdivision of the very broad $v(\mathrm{OH}) \pm k \nu$ $(\mathrm{OH}-\mathrm{Y})$ superposition band of the perturbed $\mathrm{OH}$ groups by Evans transmission window at the $2 \delta(\mathrm{OH}) \sim$ $2600 \mathrm{~cm}^{-1}$ frequency.
\end{abstract}

\section{Introduction}

In our recent IR and ab initio studies 1.2 $^{1}$ the $\sim 2800, \sim 2400$ and $\sim 1700 \mathrm{~cm}^{-1}$ infrared $\mathrm{OH}$ bands found in adsorption of many basic molecules on zeolitic Bronsted sites $^{3-18}$ were supposed to be analogous with the so-called $(A, B, C)$ triplet of $\mathrm{OH}$ bands of strong molecular $\mathrm{H}$-complexes in solutions, liquids, and solids. ${ }^{19-26}$ Although the (A,B,C) triplet had been quite well explored for these media more than 20 years ago, $19,20,24,25$ the corresponding ideas have not gained currency in the interpretation of the similar phenomenon for surfaces. Some examples of $\mathrm{H}$-complexes producing these three $\mathrm{OH}$ bands in solutions, solids, and zeolites are collected in Table 1.

Three different theories have been proposed to explain the origin of the $(\mathrm{A}, \mathrm{B}, \mathrm{C})$ triplet. According to the resonance theory by Claydon and Sheppard, ${ }^{20}$ the A, B, and $\mathrm{C}$ bands of $\mathrm{X}-\mathrm{OH}-\mathrm{Y}$ complexes are actually pseudobands, caused by the subdivision of the very broad $\mathrm{OH}$ stretching band of the perturbed $\mathrm{OH}$ group by two Evans transmission windows at $\sim 2600$ and $\sim 1900 \mathrm{~cm}^{-1}$. As Evans and Wright showed, ${ }^{27}$ when a sharp IR band overlaps a broad fundamental band of the same symmetry, this can lead to a "transmission window" in the broad band at the frequency of the sharp band. Evans gave also a theoretical interpretation of this phenomenon, ${ }^{28}$ the "missing" intensity being redistributed to both sides of the window by Fermi resonance repulsion between the vibrational levels of the superimposed bands. In the theory by Claydon and Sheppard the transmission windows were supposed to be due to Fermi resonance of the $v(\mathrm{OH}) \pm$ $k v(\mathrm{OH}-\mathrm{Y})$ combination modes, producing the broad $\mathrm{OH}$ band according to the frequency modulation theory, ${ }^{29-31}$ with the $2 \delta$ $(\mathrm{OH}) \sim 2600 \mathrm{~cm}^{-1}$ in-plane and $2 \gamma(\mathrm{OH}) \sim 1900 \mathrm{~cm}^{-1}$ outof-plane bending overtones of the perturbed $\mathrm{OH}$ group $(\nu$ $(\mathrm{OH}-\mathrm{Y})$ designates the intermolecular stretching frequency). Later this hypothesis was further theoretically developed by Bratos and Ratajczak ${ }^{20-23}$ by applying the standard techniques of nonequilibrium statistical mechanics. A semiempirical model mainly based on this theory ${ }^{23}$ reproduced very well the (A,B,C) structure of experimental IR spectra of $\mathrm{CSHSeO}_{4}$ crystals.

\footnotetext{
* Author to whom correspondence should be addressed.

${ }^{\dagger}$ Present address: Universitá degli Studi, Dipartimento di Chimica Fisica ed Elettrochimica, Via Lucini 3, 22100 Como, Italy.

\# Institute of Catalysis, Russia.

${ }^{8}$ Eindhoven University of Technology, The Netherlands.

- Abstract published in Advance ACS Abstracts, January 15, 1995.
}

TABLE 1: Wavenumbers $\left(\mathrm{cm}^{-1}\right)$ of the Three Main OH Bands of Some Hydrogen-Bonded Complexes in the $1500-3000 \mathrm{~cm}^{-1}$ Region (the A, B, and C Bands)

\begin{tabular}{|c|c|c|c|}
\hline adsorbed molecule & A & B & $\mathrm{C}$ \\
\hline \multicolumn{4}{|c|}{ Solution in $\mathrm{CCl}_{4}$} \\
\hline monochloroacetic acid & & & \\
\hline+ dimethyl sulfoxide ${ }^{a}$ & 2900 & 2545 & 1900 \\
\hline $\begin{array}{l}\text { + triphenylphosphine oxide } \\
\text { dichloroacetic acid }\end{array}$ & 2800 & 2540 & 1900 \\
\hline+ dimethyl sulfoxide ${ }^{a}$ & 2880 & 2440 & 1875 \\
\hline + triphenylphosphone oxide ${ }^{a}$ & 2750 & 2430 & 1900 \\
\hline+ dimethyl sulfoxide ${ }^{a}$ & 2750 & 2430 & 1880 \\
\hline+ triphenylphosphine oxide $^{a}$ & 2720 & 2400 & 1900 \\
\hline \multicolumn{4}{|c|}{ Solids } \\
\hline dibutylphosphinic acid ${ }^{a}$ & 2600 & 2240 & 1630 \\
\hline tolueneseleninic acid ${ }^{a}$ & 2720 & 2270 & 1660 \\
\hline dimethylarsinic acid ${ }^{a}$ & 2700 & 2350 & 1740 \\
\hline $\mathrm{KH}_{2} \mathrm{PO}_{4}{ }^{a}$ & 2750 & 2400 & 1500 \\
\hline $\mathrm{NaH}_{3}\left(\mathrm{SeO}_{3}\right)_{2}{ }^{a}$ & 2750 & 2350 & 1600 \\
\hline \multicolumn{4}{|c|}{ Zeolitic OH Group } \\
\hline+ dimethyl ether ${ }^{b}$ & 2900 & 2500 & $1900-1300$ \\
\hline+ diethyl ether ${ }^{b}$ & 2950 & 2300 & $1900-1300$ \\
\hline+ tetrahydrofuran $^{b}$ & & 2370 & $1900-1300$ \\
\hline+ di- $n$-butyl ether ${ }^{b}$ & 2900 & 2300 & $1900-1300$ \\
\hline+ acetone $e^{b, c}$ & 2900 & 2370 & $1800-1300$ \\
\hline$+n$-butyraldehyde ${ }^{b}$ & 2900 & 2400 & $1700-1300$ \\
\hline+ acetonitrile $e^{b, d}$ & 2820 & 2430 & 1700 \\
\hline+ benzonitrile $b$ & 2800 & 2360 & \\
\hline+ formic acid $b$ & 2900 & 2460 & $1700-1300$ \\
\hline+ acetic acid $b$ & 2900 & 2470 & $1800-1300$ \\
\hline+ diethyl ketone ${ }^{c}$ & 2850 & 2400 & \\
\hline+ mesityl ketone ${ }^{c}$ & 2850 & 2400 & \\
\hline+ water $^{b, e}$ & 2900 & 2450 & 1700 \\
\hline+ methanolf & 2900 & 2450 & 1700 \\
\hline
\end{tabular}

${ }^{a}$ Reference $19 .{ }^{b}$ Reference $3 .{ }^{c}$ Reference $4 .{ }^{d}$ Reference 5. ${ }^{e}$ References $6-11 .{ }^{f}$ References $12-18$.

However, unlike the original theory, ${ }^{20}$ in ref 23 the $\mathrm{C}$ band was associated with a $\delta(\mathrm{OH})+v(\mathrm{SeO})$ combination band enhanced by the resonance with the $v(\mathrm{OH}) \pm k v(\mathrm{OH}-\mathrm{Y})$ band, $v(\mathrm{SeO})$ corresponding to an intermolecular vibration of the $\mathrm{OH}$ group oxygen.

Also another theory has been suggested ${ }^{19,24-26}$ which supposes the $(\mathrm{A}, \mathrm{B}, \mathrm{C})$ triplet to originate from Fermi resonance of the $\nu(\mathrm{OH})$ with $2 \delta(\mathrm{OH})$ and $2 \gamma(\mathrm{OH})$ levels. As distinct from the theory by Claydon and Sheppard, it considers the A, B, and 
$\mathrm{C}$ bands of $\mathrm{X}-\mathrm{OH}-\mathrm{Y}$ complexes to be individual IR bands corresponding to the $2 \delta(\mathrm{OH}), v(\mathrm{OH})$, and $2 \gamma(\mathrm{OH})$ frequencies, respectively, with the $\mathrm{A}$ and $\mathrm{C}$ bands being strongly enhanced and shifted by the $2 \delta(\mathrm{OH}) \rightarrow \nu(\mathrm{OH}) \rightarrow 2 \gamma(\mathrm{OH})$ resonance interactions with respect to the unperturbed $2 \delta(\mathrm{OH})$ and $2 \gamma$ $(\mathrm{OH})$ frequencies. ${ }^{25,26}$ In this interpretation two "holes" between the A, B, and C bands are not taken to be Evans windows. A semiempirical model developed by Odinokov et al. ${ }^{25,26}$ was successfully applied for predicting the $C$ band maximum and the A + B band "center of gravity" wavenumbers ${ }^{25}$ for a wide range of H-complexes of benzoic, acetic, monoacetic, and triacetic acids. As to the application of this theory to surfaces, it was used by Angell and Howell ${ }^{5}$ to explain an unexpected experimental result that acetonitrile complex with the structural $\mathrm{OH}$ group of $\mathrm{HY}$ zeolite, which should have only one $\mathrm{OH}$ stretching mode, generates two $\mathrm{OH}$ bands at 2800 and 2400 $\mathrm{cm}^{-1}$.

The third theory, the double-minimum theory, ${ }^{19,32-35}$ postulates that the $(\mathrm{A}, \mathrm{B}, \mathrm{C})$ infrared structure of strong $\mathrm{H}$-complexes is produced by a pair of quasigenerate vibrational levels of an asymmetric double-minimum proton potential, corresponding to the "neutral" $\mathrm{X}-\mathrm{OH}-\mathrm{Y}$ and "ionic" $\mathrm{X}-\mathrm{O}^{-}-\mathrm{HY}^{+}$states of these complexes. Considering the proton tunneling through the potential barrier between two minima, the selection rules for transitions amongst the lowest levels in such a potential permit four of the infrared active modes. As the separation between the corresponding $\mathrm{OH}$ bands and their intensity depend on the exact shape of the potential, only three or fewer bands may be found under certain circumstances. So far, no quantitative agreement has been obtained between spectral characteristics of an observed $(A, B, C)$ triplet and the results of their calculations using a suitable double-minimum potential. As Hadzi noticed, ${ }^{19}$ the chances of such agreement are very small. It is necessary either to have a very good model to start from or to carry out an immense number of calculations in view of the large number of physically possible double-minimum situations and the lack of initial data. Nevertheless, this model of strong $\mathrm{H}$ bonding is in wide use now. In an experimental study by Kubelkova et al. ${ }^{4}$ it was utilized for the interpretation of IR spectra of acetone, diethyl ketone, and mesityl ketone adsorption on Bronsted sites of H-ZSM5 zeolite: the $\sim 2800$ and $\sim 2400 \mathrm{~cm}^{-1}$ bands were associated with the "neutral" and "ionic" states of the adsorption H-complexes. Also, in an IR study by Parker et al. ${ }^{3}$ these $\mathrm{OH}$ bands found in adsorption of many other basic sorbants on $\mathrm{H}$ ZSM5 were explained in terms of the double-minimum model.

In our recent studies ${ }^{1,2}$ the $\sim 2800, \sim 2400$, and $\sim 1700 \mathrm{~cm}^{-1}$ $\mathrm{OH}$ bands of zeolitic H-complexes were supposed to conform to the resonance theory by Claydon and Sheppard. The main change in the interpretation of IR spectra of surface Hcomplexes, caused by the extension of this theory to surfaces, results from the fact that the $\sim 2800, \sim 2400$, and $\sim 1700 \mathrm{~cm}^{-1}$ bands should be associated not with three different $\mathrm{OH}$ modes of these complexes, as generally accepted in the literature now, ${ }^{3-18}$ but with the $v(\mathrm{OH})$ mode of the perturbed $\mathrm{OH}$ group only. For example, in previous experimental IR studies $^{8-10,12,14,17,18}$ of water and methanol complexes with the zeolitic $\mathrm{OH}$ group the 2900,2450 , and $1700 \mathrm{~cm}^{-1}$ bands were assigned to the antisymmetric, symmetric, and deformation $\mathrm{OH}$ vibrations of $\mathrm{H}_{3} \mathrm{O}^{+}$and $\mathrm{CH}_{3} \mathrm{OH}_{2}{ }^{+}$ions, respectively. As shown in ref 2 , the resonance theory suggests a substantially new assignment of $\mathrm{OH}$ bands for these complexes and leads to the conclusion that they are "neutral". Considering numerous IR studies devoted to surface $\mathrm{H}$-complexes during the last 50 years, a modern reconsideration of their IR data on the basis of the resonance theory can lead to a significant revision of many other previously accepted interpretations. To justify such utilization of the resonance theory, its experimental proof becomes very topical, in view of the fact that at present this theory can be regarded as only a fairly reasonable one, for it has not been rigorously proved for a concrete case of the $(\mathrm{A}, \mathrm{B}, \mathrm{C})$ triplet. As follows from above, this has a direct bearing also on discriminating between the single-minimum model of strong $\mathrm{H}$ bonding, tacitly assumed by the resonance theory, and the doubleminimum model. Also an experimental validation of the analogy between the (A,B,C) triplet of molecular H-complexes and the $\sim 2800, \sim 2400$, and $\sim 1700 \mathrm{~cm}^{-1} \mathrm{OH}$ bands of surface $\mathrm{H}$-complexes is very important, considering that the phenomenon of the $(A, B, C)$ triplet has never been specially studied for surface $\mathrm{H}$-complexes.

Here the $(A, B, C)$ triplet is investigated for surface Hcomplexes using $\mathrm{CD}_{3} \mathrm{CN}$ and $\mathrm{CCl}_{3} \mathrm{CN}$ adsorptions on deuterated H-ZSM5 and H-FeSil zeolites. A direct experimental proof will be given for the first time in the study of this phenomenon that the wavenumber of the minimum between the $\mathrm{A}$ and $\mathrm{B}$ bands of D-complexes is nearly equal to the $2 \delta(\mathrm{OD})$ overtone frequency of the perturbed OD group. This verifies the hypotheses by Claydon and Sheppard about the nature of the $\mathrm{A}$ and $\mathrm{B}$ bands.

\section{Experimental Section}

Zeolites. ZSM-5 was synthesized hydrothermally at $443 \mathrm{~K}$ for $48 \mathrm{~h}$ with $\mathrm{TPABr}$ as a templating agent. $\mathrm{A} \mathrm{Si} / \mathrm{Al}=52$ ratio for this zeolite was estimated on the basis of adsorption calorimetric measurements, taking an amount of the adsorbed ammonia at $423 \mathrm{~K}$ as a measure of the SiOHAl lattice sites. ${ }^{36}$

MFI ferrosilicate FeSil was prepared using iron sulfate and silicate solution as described in detail in ref $37 . \mathrm{A} \mathrm{Si} / \mathrm{Fe}=32$ ratio was determined by adsorption calorimetric measurements (see above).

Deuteration was performed by reacting the activated samples for $1.5 \mathrm{~h}$ at $623 \mathrm{~K}$ with $100 \mathrm{mbar}$ of $\mathrm{D}_{2}$.

IR Measurements. IR spectra were recorded at room temperature using a Bruker IFS $113 \mathrm{v}$ FTIR spectrometer with a heatable vacuum cell. The samples were pressed into $7.5 \mathrm{mg} /$ $\mathrm{cm}^{2}$ disks. Before gas dosage the samples were activated for 1 $h$ at $723 \mathrm{~K}$ under $10^{-6}$ mbar pressure.

\section{Results and Discussion}

In agreement with recent experimental studies by Jacobs et al. ${ }^{38,39} \mathrm{H} \rightarrow \mathrm{D}$ exchange of H-ZSMS and H-FeSil zeolites gives rise to the $\delta(O D)$ bands of the bridging SiODAl and SiODFe groups at 894 and $865 \mathrm{~cm}^{-1}$, respectively, between the very intense bands of symmetric $\left(600-800 \mathrm{~cm}^{-1}\right)$ and antisymmetric $\left(1000-1300 \mathrm{~cm}^{-1}\right)$ lattice stretching vibrations $\mathrm{s}^{40,41}$ of these zeolites. Figure 1 and Table 2 show the changes of these bands caused by the $\mathrm{CD}_{3} \mathrm{CN}$ and $\mathrm{CCl}_{3} \mathrm{CN}$ adsorptions. According to our IR and ab initio studies of $\mathrm{CD}_{3} \mathrm{CN}$ interaction with zeolitic $\mathrm{OH}$ groups, ${ }^{1}$ these adsorptions should result in the formation of four different medium-strong D-complexes.

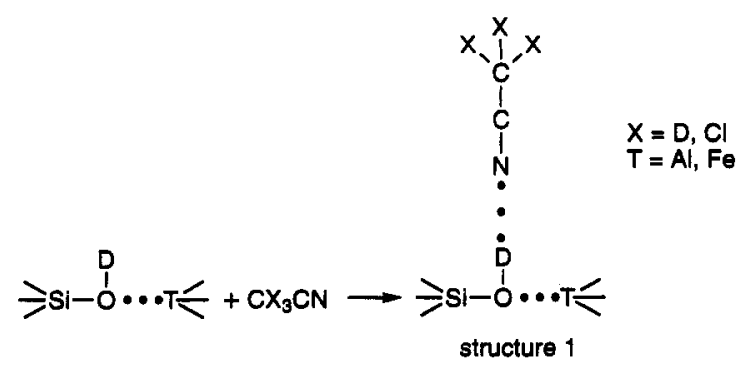



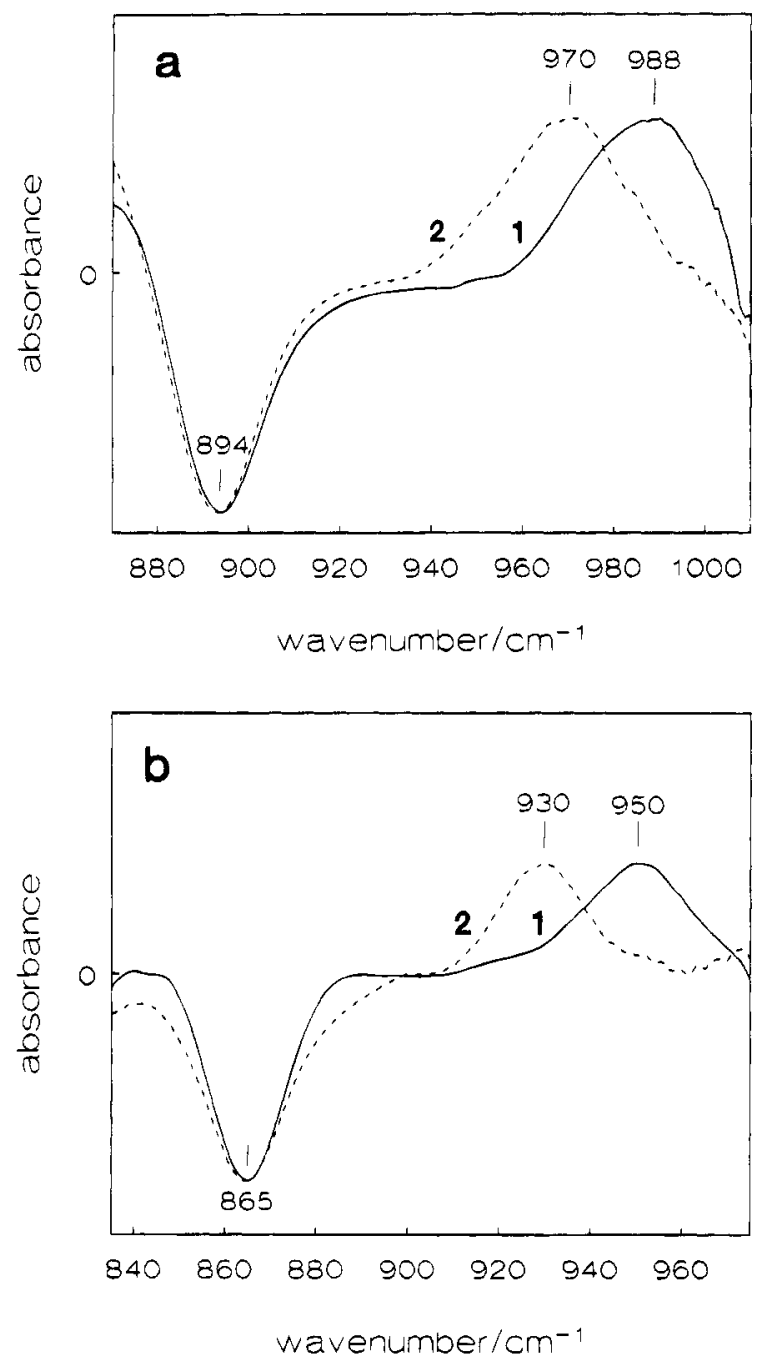

Figure 1. Changes of the $\delta(O D)$ bands of (a) H-ZSM5 induced by $\mathrm{CD}_{3} \mathrm{CN}$ (1) and $\mathrm{CCl}_{3} \mathrm{CN}$ (2) adsorption at $295 \mathrm{~K}$ and $0.05 \mathrm{mbar}$ (in different arbitrary absorbance units); (b) $\mathrm{H}$-FeSil induced by $\mathrm{CD}_{3} \mathrm{CN}$ adsorption at $295 \mathrm{~K}$ and $0.05 \mathrm{mbar}$ (1) and $\mathrm{CCl}_{3} \mathrm{CN}$ adsorption at 295 $\mathrm{K}$ and 1.36 mbar (2) (in different arbitrary absorbance units).

TABLE 2: $\delta(O D)$ Band and Transmission Window Minimum Wavenumbers $\left(\mathrm{cm}^{-1}\right)$

\begin{tabular}{|c|c|c|c|c|c|c|}
\hline \multirow{2}{*}{$\begin{array}{l}\text { Bronsted } \\
\text { site }\end{array}$} & \multirow[b]{2}{*}{$\delta(\mathrm{OD})$} & \multicolumn{3}{|c|}{$\mathrm{CD}_{3} \mathrm{CN}$ adsorption } & \multicolumn{2}{|c|}{$\begin{array}{c}\mathrm{CCl}_{3} \mathrm{CN} \\
\text { adsorption }\end{array}$} \\
\hline & & $\overline{\delta(\mathrm{OD})}$ & $\Delta \delta(\mathrm{OD})$ & window & $\overline{\delta(\mathrm{OD})}$ & $\overline{\Delta \delta(\mathrm{OD})}$ \\
\hline SiODAl & & 088 & 04 & 1977 & $\begin{array}{l}970 \\
930\end{array}$ & $\begin{array}{l}76 \\
65\end{array}$ \\
\hline
\end{tabular}

${ }^{a}$ Twice the $\delta(\mathrm{OH})$ frequency of the perturbed $\mathrm{OH}$ group.

Both the small $\Delta \delta(O D)=65-95 \mathrm{~cm}^{-1}$ upward frequency shift and the insignificant change of the $\delta(\mathrm{OD})$ band intensity in these interactions (Figure 1 and Table 2) are in good agreement with previous experimental studies of the $\mathrm{OH}(\mathrm{OD})$ bending mode for molecular $H(D)$-complexes. ${ }^{42}$ The $\Delta \delta(O D)$ shift increases upon replacing $\mathrm{CCl}_{3} \mathrm{CN}$ with $\mathrm{CD}_{3} \mathrm{CN}$ (by $\sim 20 \mathrm{~cm}^{-1}$ ) and upon replacing SiODFe with SiODAl (by $\sim 10 \mathrm{~cm}^{-1}$ ) in structure 1 due to the strengthening of the acid-base interaction by these replacements, $\mathrm{CD}_{3} \mathrm{CN}$ being more basic compared with $\mathrm{CCl}_{3}-$ $\mathrm{CN}$ and SiODAl being more acidic compared with SiODFe. ${ }^{37}$ This also agrees with IR studies of the $O H(O D)$ bending mode for molecular $\mathrm{H}(\mathrm{D})$-complexes. ${ }^{42}$

It is to be noted that in previous experimental studies of the (A,B,C) triplet, performed mainly for H-complexes of organic acids in solutions and liquids, the $\delta(\mathrm{OD})$ band fell into the heavily populated "fingerprint" spectral region of these compounds at $500-1500 \mathrm{~cm}^{-1} \cdot 19,20,42$ The identification of the $\delta$ (OD) band is known to be very difficult in this case. ${ }^{42}$ In an experimental study by Claydon and Sheppard ${ }^{20} \mathrm{H} \rightarrow \mathrm{D}$ exchange combined with low-temperature IR techniques was used in order to locate accurately the $\delta(\mathrm{OH})$ fundamental for $\mathrm{H}$-complexes of liquid phenylphosphonic and dibutylarsinic acids. As a result of this investigation, the conclusion was made that the $2 \delta(\mathrm{OH})$ frequency of these two complexes corresponds approximately not with the $A$ band maximum, as one could expect according to a previously proposed ${ }^{19,24}$ interpretation of the $(A, B, C)$ triplet, but with the minimum between the $A$ and $B$ bands. However, the found difference between the minimum wavenumber and the $2 \delta(\mathrm{OH})$ frequency $\left(\sim 100 \mathrm{~cm}^{-1}\right.$ for dibutylarsinic acid) was too large for this result to be regarded as an experimental proof of the resonance theory. ${ }^{20}$ Therefore, an alternative theoretical interpretation was suggested later ${ }^{25.26}$ for the $(A, B, C)$ infrared structure by Odinokov et al. (see the Introduction). In the present study an attempt is undertaken to prove the resonance theory of the $(\mathrm{A}, \mathrm{B})$ doublet by comparing the $2 \times \delta(\mathrm{OD})$ frequency with the wavenumber of the minimum between the $\mathrm{A}$ and $\mathrm{B}$ OD bands for the above-mentioned zeolitic Dcomplexes. According to refs 20,25, and 26, this transmission window should be significantly narrower for $\mathrm{D}$-complexes as compared with $\mathrm{H}$-complexes. This is accounted for $^{20}$ by a strong weakening of the Fermi coupling between the stretching fundamental and the bending overtone due to the anharmonicity decrease by $\mathrm{H} \rightarrow \mathrm{D}$ exchange. ${ }^{25,26}$ As follows from theoretical constructions of the window for cases of a comparatively weak Fermi resonance, ${ }^{21}$ we can expect the wavenumber of the minimum between the $A$ and $B O D$ bands to be equal to the $2 \times \delta(\mathrm{OD})$ frequency within a few $\mathrm{cm}^{-1}$ if the resonance theory is correct. Assuming $2 \delta(\mathrm{OD}) \cong 2 \times \delta(\mathrm{OD})$, the anharmonicity of the $\delta(\mathrm{OD})$ vibration is thus neglected. This is not believed to be a serious error, as the $\mathrm{X}_{\delta \delta}$ anharmonicity constant of $\delta$ $(\mathrm{XH})$ bending modes is known to be very small ${ }^{25}$ (see also below). As an example, the wavenumber of a narrow Evans window in the OD stretching band of $\mathrm{OD}_{2}$ complexes with $\mathrm{Na}^{+}$ and $\mathrm{Ag}^{+}$cations in $\mathrm{Na}_{x} \mathrm{Ag}_{y} \mathrm{~A}$ zeolites (the $\mathrm{OD}$ groups are nonbonded in this case) was found by Baumann et al. ${ }^{43}$ to be equal to the $2 \times \delta(\mathrm{OD})$ frequency to an accuracy of a few $\mathrm{cm}^{-1}$.

Figure 2 shows the changes in the $1300-4000 \mathrm{~cm}^{-1}$ spectral region for $\mathrm{CD}_{3} \mathrm{CN}$ and $\mathrm{CCl}_{3} \mathrm{CN}$ adsorptions on H-ZSM5, H-FeSil, H/D-ZSM5, and H/D-FeSil zeolites. Two broad OH bands appear at $\sim 2800$ and $\sim 2400 \mathrm{~cm}^{-1}$ in the adsorptions on the H-zeolites, typical for medium-strong $\mathrm{X}-\mathrm{OH}-\mathrm{Y}$ molecular complexes in solutions, liquids, and solids, ${ }^{19,20,25,26}$ the so-called $\mathrm{A}$ and $\mathrm{B}$ bands. For molecular $\mathrm{H}$-complexes they are usually accompanied by another broad $\mathrm{OH}$ band at $\sim 1700 \mathrm{~cm}^{-1}$, the $\mathrm{C}$ band. ${ }^{19,20,25,26}$ In Figure 2 the $\mathrm{C}$ band can be found only for the $\mathrm{CD}_{3} \mathrm{CN}$ complex with the SiOHAl group, being the strongest of the four $\mathrm{H}$-complexes involved. This fact agrees with an IR spectroscopic regularity ${ }^{44}$ for molecular $\mathrm{H}$-complexes in solutions: ${ }^{19,26}$ in a series of closely related $\mathrm{X}-\mathrm{OH}-\mathrm{Y}$ complexes the $\mathrm{C}$ band intensity increases on strengthening the acid-base interaction. On going from the $\mathrm{H}$ - to H/D-zeolites (Figure 2), the intensity of the $\mathrm{A}$ and $\mathrm{B} \mathrm{OH}$ bands decreases and broad, complex $O D$ bands appear in the $1700-2300 \mathrm{~cm}^{-1}$ region due to the frequency isotopic shift. As shown for H-complexes of organic acids, ${ }^{19,20} \mathrm{H} \rightarrow \mathrm{D}$ exchange causes the $\mathrm{A}$ and $\mathrm{B}$ bands to shift to $\sim 2000$ and $\sim 1750 \mathrm{~cm}^{-1}$. The corresponding C OD band has not been definitively resolved in the very complex $500-1500 \mathrm{~cm}^{-1}$ spectral region of these complexes. ${ }^{3,20}$ Also for zeolites the $C$ OD band should be obscured in the 1000$1300 \mathrm{~cm}^{-1}$ region of the antisymmetric lattice vibrations. 

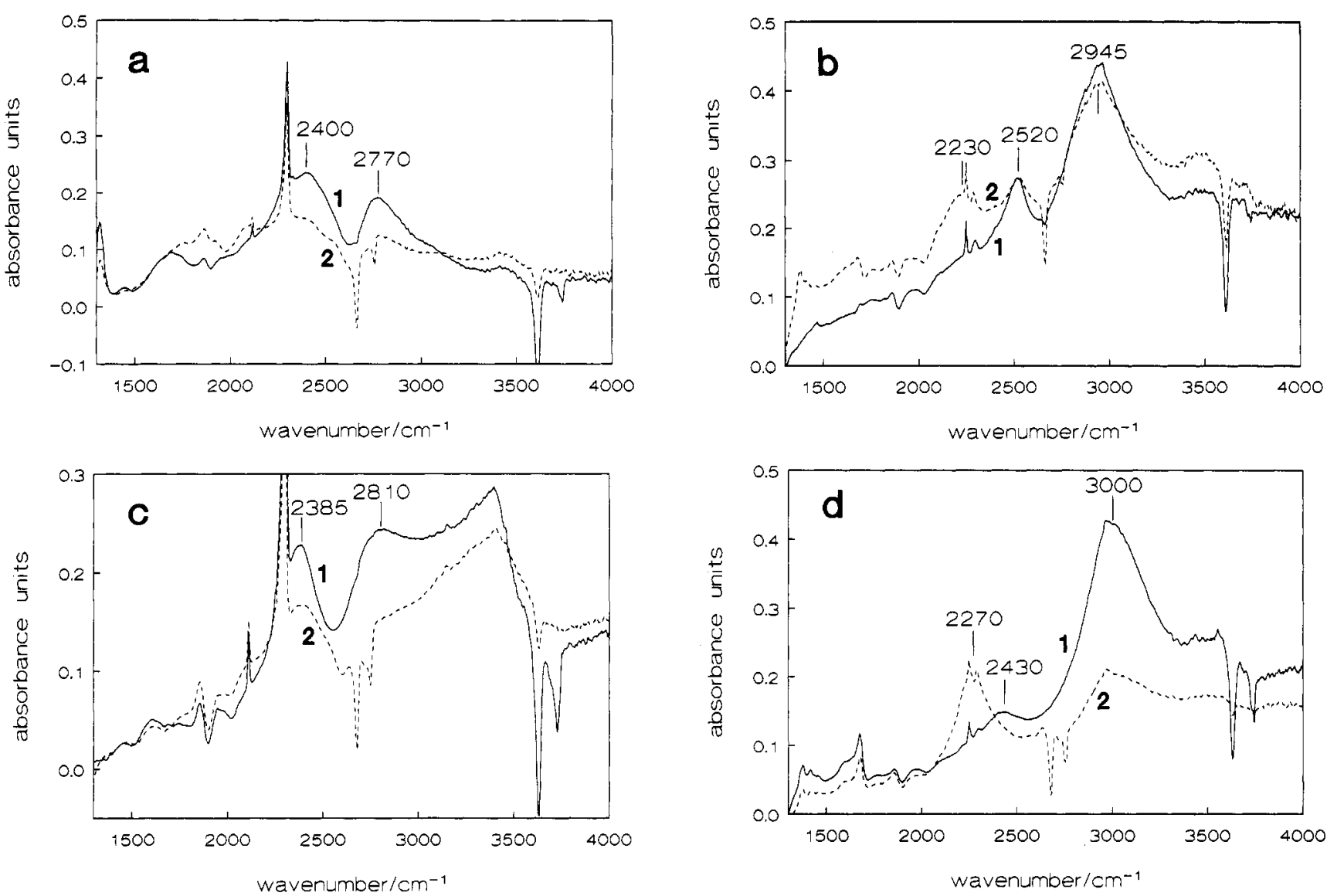

Figure 2. Changes in the $1500-4000 \mathrm{~cm}^{-1}$ range of (a) H-ZSM5 (1) and H/D-ZSM5 (2) induced by $\mathrm{CD}_{3} \mathrm{CN}$ adsorption at $295 \mathrm{~K}$ and $0.05 \mathrm{mbar}$; (b) H-ZSM5 (1) and H/D-ZSM5 (2) induced by $\mathrm{CCl}_{3} \mathrm{CN}$ adsorption at $295 \mathrm{~K}$ and $0.05 \mathrm{mbar}$; (c) H-FeSil (1) and $\mathrm{H} / \mathrm{D}-\mathrm{FeSil}(2)$ induced by $\mathrm{CD}_{3} \mathrm{CN}$ adsorption at $295 \mathrm{~K}$ and 0.05 mbar; (d) H-FeSil (1) and $\mathrm{H} / \mathrm{D}-\mathrm{FeSil}$ (2) induced by $\mathrm{CCl}_{3} \mathrm{CN}$ adsorption at $295 \mathrm{~K}$ and $1.36 \mathrm{mbar}$.

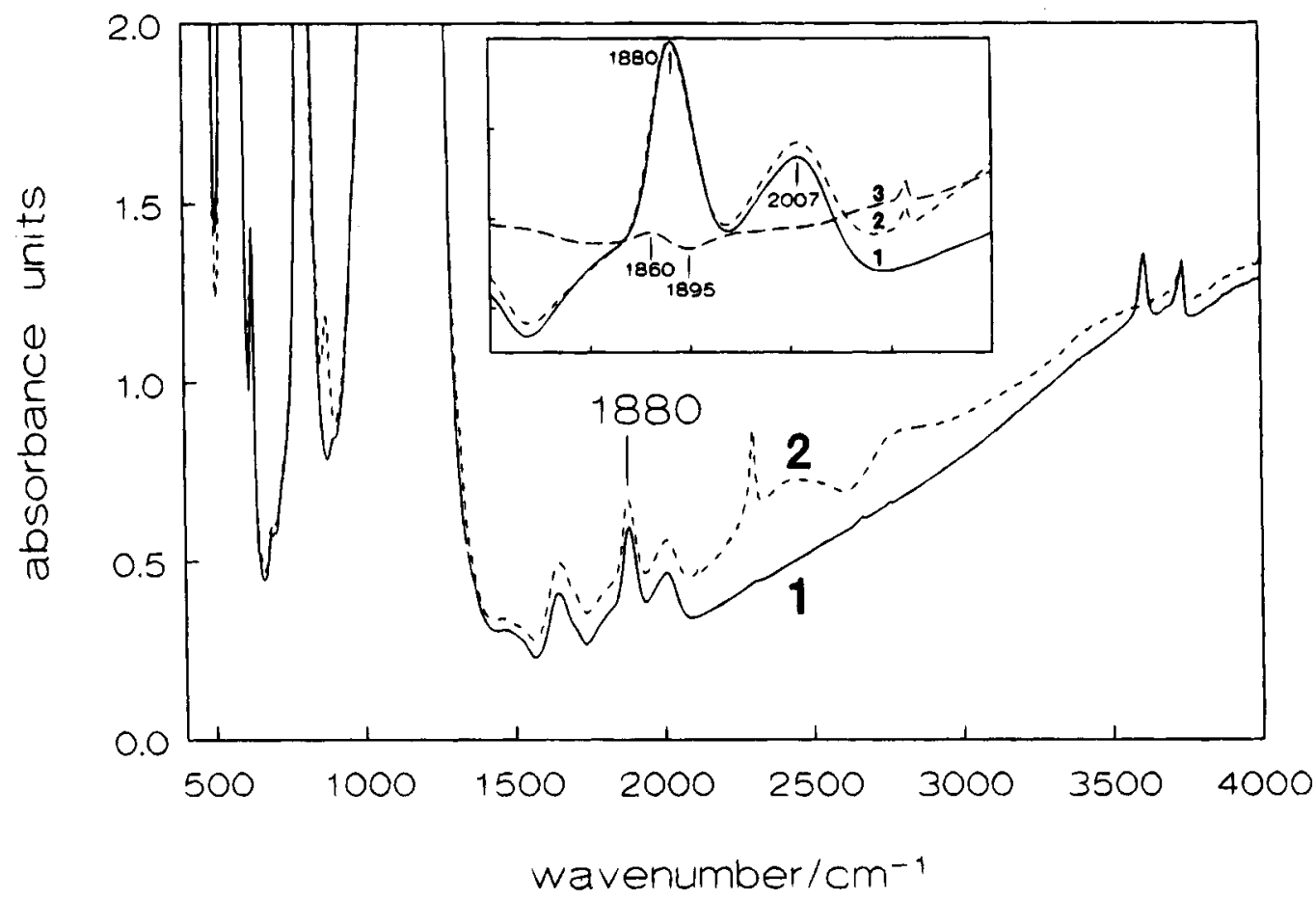

Figure 3. $500-4000 \mathrm{~cm}^{-1}$ range of H-ZSM5 (1) and that induced by $\mathrm{CD}_{3} \mathrm{CN}$ adsorption at $295 \mathrm{~K}$ and 0.05 mbar (2). The inset illustrates the appearance of the "imaginary" positive and negative bands at 1860 and $1895 \mathrm{~cm}^{-1}$ in the difference spectrum 3 as a result of the $1880 \mathrm{~cm}^{-1}$ band subtraction of the unloaded zeolite (spectrum 1) from that negligibly shifted to higher frequency by the adsorption (spectrum 2 ).

Neither the $\mathrm{OH}$ nor the OD bands (Figures 1 and 2) can be directly used to check whether the transmission window position between the $A$ and $B$ bands corresponds to the in-plane bending overtone. For the perturbed SiOHAl and SiOHFe groups this window is well-pronounced in the spectra at $\sim 2600 \mathrm{~cm}^{-1}$ (Figure 2 as an example), but the corresponding $\delta(\mathrm{OH})$ in-plane bending band falls in the $1000-1300 \mathrm{~cm}^{-1}$ region of lattice vibrations (see Figure 3). This makes the zeolitic $\mathrm{OH}$ groups 
useless for the following consideration. For the perturbed SiODAl and SiODFe groups the $\delta(O D)$ band is well-defined (Figure 1), but the $1800-2000 \mathrm{~cm}^{-1}$ region, where the corresponding Evans window is expected to appear, according to the $2 \times \delta(\mathrm{OD})$ frequencies (Table 2 ), is strongly complicated by two intense lattice bands 7,45 at 1880 and $2007 \mathrm{~cm}^{-1}$ (Figure 3). Also in the difference spectra this region remains too complex for a definitive interpretation as the subtraction of the 1880 and $2007 \mathrm{~cm}^{-1}$ bands of the unloaded zeolites from these slightly shifted by the adsorption produces "imaginary" positive and negative bands here (Figure 2 and the inset in Figure 3). This complication of difference spectra through the 1880 and 2007 $\mathrm{cm}^{-1}$ bands is usual for IR experimental studies of adsorption on zeolites. $3,7,10,46$ A unique procedure of separation of the (A,B) OD doublet of interest from these two bands is suggested below.

The spectra recorded after the adsorption on the deuterated and hydrogen forms of zeolites in the $1800-2000 \mathrm{~cm}^{-1}$ region (Figure 2) can be written, respectively, as

$$
S^{d}=S_{O D}^{d}+S_{L}^{d}+S_{O H}^{d}
$$

and

$$
S^{\mathrm{h}}=S_{\mathrm{OH}}^{\mathrm{h}}+S_{\mathrm{L}}^{\mathrm{h}}
$$

$S_{\mathrm{OD}}, S_{\mathrm{OH}}$, and $S_{\mathrm{L}}$ designating the $\mathrm{OD}, \mathrm{OH}$, and lattice 1880 and $2007 \mathrm{~cm}^{-1}$ bands. Assuming the lattice vibrations to be independent of the $\mathrm{H} \rightarrow \mathrm{D}$ exchange, ${ }^{47}$ that means

$$
S_{\mathrm{L}}^{\mathrm{d}}=S_{\mathrm{L}}^{\mathrm{h}}
$$

$S_{\text {OD }}^{d}$ can be written as

$$
S_{\mathrm{OD}}^{\mathrm{d}}=\left(S^{\mathrm{d}}-S^{\mathrm{h}}\right)-\left(S_{\mathrm{OH}}^{\mathrm{d}}-S_{\mathrm{OH}}^{\mathrm{h}}\right)
$$

As $S_{\mathrm{OH}}^{\mathrm{d}}$ and $S_{\mathrm{OH}}^{\mathrm{h}}$ are smooth low-frequency tails of the $\mathrm{OH}$ bands in the $1800-2000 \mathrm{~cm}^{-1}$ region (see Figures 2 and 3), the term $\left(S_{\mathrm{OH}}^{\mathrm{d}}-S_{\mathrm{OH}}^{\mathrm{h}}\right)$ can be neglected in (5), being capable of changing only a base line of the $S_{\mathrm{OD}}^{\mathrm{d}}$ spectra. In Figure 4 the $S_{\mathrm{OD}}^{\mathrm{d}}$ curves are presented for the $\mathrm{CD}_{3} \mathrm{CN}$ adsorptions on $\mathrm{H}$-ZSM5 and H/D-FeSil, constructed as

$$
S_{\mathrm{OD}}^{\mathrm{d}}=\left(S^{\mathrm{d}}-S^{\mathrm{h}}\right)
$$

The transmission windows become clearly observable in these spectra at 1977 and $1902 \mathrm{~cm}^{-1}$, very close to their expected values of $2 \times 988=1976$ and $2 \times 950=1900 \mathrm{~cm}^{-1}$ (see Table 2) according to the resonance theory. This verifies the hypotheses by Claydon and Sheppard about the nature of the $(\mathrm{A}, \mathrm{B})$ doublet. The negligible difference between the window positions and the $2 \times \delta(O D)$ values is an indication of a very small value of the anharmonicity constant,

$$
X_{\delta \delta}^{\mathrm{OD}}=(2 \delta(\mathrm{OD})-2 \times \delta(\mathrm{OD})) / 2
$$

for the hydrogen-bonded OD groups. In an ab initio study by Mix et al. ${ }^{48}$ the $X_{\delta \delta}^{\mathrm{OH}}$ of the free zeolitic $\mathrm{OH}$ groups was found to be equal to $-4 \mathrm{~cm}^{-1}$. This shows the contribution to the potential curve of the bending vibration from the $\mathrm{H}$ bonding to be harmonic with high precision. In agreement with ref 20 , the transmission windows between the $\mathrm{A}$ and $\mathrm{B}$ bands are significantly narrower for the D-complexes compared with the H-complexes (cf. Figures 2 and 4).

The same procedure of the $S_{\mathrm{OD}}^{\mathrm{d}}$ construction for the $\mathrm{CCl}_{3} \mathrm{CN}$ adsorption on H/D-ZSM5 and H/D-FeSil (the spectra are not
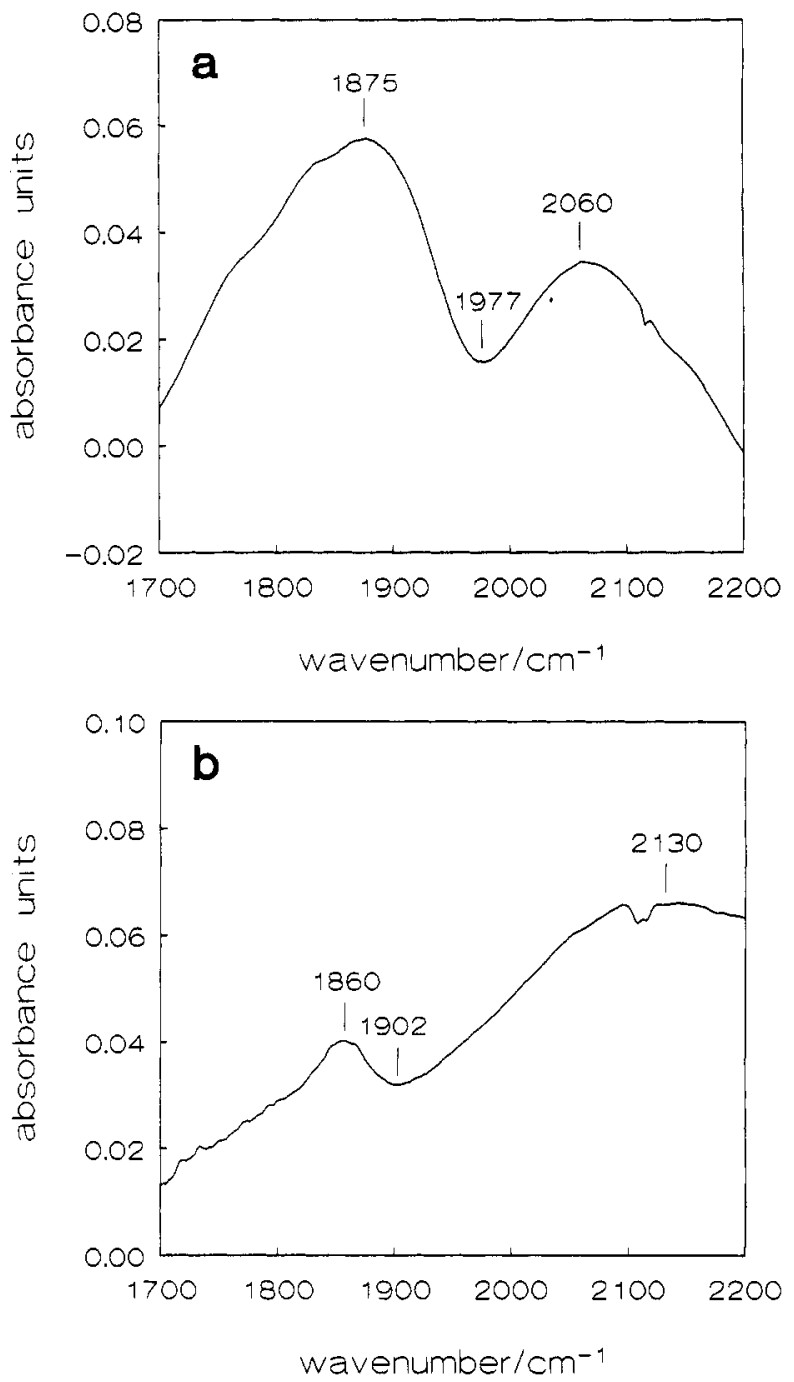

Figure 4. $S_{\mathrm{OD}}^{\mathrm{d}}$ spectra of (a) H/D-ZSM5 with $\mathrm{CD}_{3} \mathrm{CN}$ at $295 \mathrm{~K}$ and 0.05 mbar; (b) H/D-FeSil with $\mathrm{CD}_{3} \mathrm{CN}$ at $295 \mathrm{~K}$ and 0.05 mbar.

presented) shows that this molecule is not basic enough to provide the shift of the $v(\mathrm{OD}) \pm k v(\mathrm{OD} \times \mathrm{B})$ band to the $1800-$ $2000 \mathrm{~cm}^{-1}$ region of the $2 \delta(\mathrm{OD})$ overtone.

\section{Conclusion}

The IR study of $\mathrm{CD}_{3} \mathrm{CN}$ and $\mathrm{CCl}_{3} \mathrm{CN}$ adsorption on $\mathrm{H} / \mathrm{D}$ ZSM5 and H/D-FeSil zeolites shows the $\sim 2800$ and $\sim 2400$ $\mathrm{cm}^{-1} \mathrm{OH}$ bands found in adsorption of many basic molecules on zeolites to be analogous to the so-called A and $\mathrm{B} \mathrm{OH}$ bands of strong molecular $\mathrm{H}$-complexes in solutions, liquids, and solids. A direct experimental proof of the resonance theory of these bands by Claydon and Sheppard is suggested. According to this theory the $\mathrm{A}$ and $\mathrm{B}$ bands of medium-strong $\mathrm{X}-\mathrm{OH}-\mathrm{Y}$ complexes are actually pseudobands caused by the subdivision of the very broad $\mathrm{OH}$ stretching band by Evans transmission window at the $2 \delta(\mathrm{OH})$ bending overtone frequency.

Acknowledgment. We thank Dr. G. Vorbeck (Eindhoven University of Technology) for preparation of the samples.

\section{References and Notes}

(1) Pelmenschikov, A. G.; van Santen, R. A.; Jänchen, J.; Meijer, E. J. Phys. Chem. 1993, 97, 11071. 10678 . 
(3) Parker, L. M.; Bibby, D. M.; Burns, G. R. In Zeolites: Facts, Figures, Future; Jacobs, P. A., van Santen, R. A., Eds.; Elsevier: Amsterdam, 1988; p 963

(4) Kubelkova, L.; Cejka, J.; Novakova, J. Zeolites 1991, 11, 48.

(5) Angel, C. L.; Howell, M. V. J. Phys. Chem. 1969, 73, 2551.

(6) Parker, L. M.; Bibby, D. M.; Burns, G. R. Zeolites 1991, 11, 293.

(7) Parker, L. M.; Bibby, D. M.; Bums, G. R. Zeolites 1993, 13, 107.

(8) Jentys, A.; Warecka, G.; Derewenski, M.; Lercher, J. A. J. Chem. Phys. 1989, 93, 4837. 309.

(9) Jentys, A.; Warecka, G.; Lercher, J. A. J. Mol. Catal. 1989, 51 ,

(10) Marchese, L.; Chen, J.; Wright, P. A.; Thomas, J. M. J. Phys. Chem. $1993,97,8109$.

(11) Corma, A.; Agudo, A. L.; Fornes, V. J. Chem. Soc., Chem. Commun. 1983, 942.

(12) Mirth, G.; Lercher, J. A.; Anderson, M. W.; Klinowski, J. J. Chem. Soc., Faraday Trans. 1990, 86 (17), 3039.

(13) Ison, A.; Gorte, R. J. J. Catal. 1984, 89, 150.

(14) Mirth, G.; Kogelbauer, A.; Lercher, J. A. In 9th Int. Zeol. Conf., Extended Abstracts; Higgens, et al., Eds.; Butterword: Montreal, 1992; p A15. 441.

(15) Kubelkova, L.; Novakova, J.; Nodomova, K. J. Catal. 1990, 124,

(16) Salvador, P.; Kladnig, W. J. Chem. Soc., Faraday Trans. 1 1977, 73,1153 .

(17) Mirth, G.; Kogelbauer, A.; Lercher, J. A. In Proceedings of the 9th Intermational Zeolite Conference, Montreal, 1992; van Ballmoos, R., Higgins, J. B., Treacy, M. M. J., Eds.; Butterworth-Heinemann: London, 1992; Vol. 1, p 251.

(18) Mirth, G.; Lercher, J. A. J. Phys. Chem. 1991, 95, 3736.

(19) Hadzi, D. Pure Appl. Chem. 1965, 11, 435.

(20) Clydon, M. F.; Sheppard, N. Chem. Commun. 1969, 1431.

(21) Bratos, S. J. Chem. Phys. 1976, 63, 3499.

(22) Bratos, S.; Ratajczak, H. J. Chem. Phys. 1982, 76, 77. 235 .

(23) Ratajczak, H.; Yaremko, A.; Baran, J. J. Mol. Struct. 1992, 275,

(24) Ratajczak, H. J. Mol. Struct. 1969, 12, 287.

(25) Odinokov, S. E.; logansen, A. V. Spectrochim. Acta 1972, 28A, 2343.

(26) Odinokov, S. E.; Mashkovsky, A. A.; Glazunov, V. P.; Iogansen,

A. V.; Rassadin, B. V. Spectrochim. Acta 1976, 32, 1355.

(27) Evans, J. C.; Wright, N. Spectrochim. Acta 1960, 16, 352.

(28) Evans, J. C. Spectrochim. Acta 1960, 16, 994.

(29) Batuev, M. I. Izvest. Akad. Nauk SSSR, ser. Fiz. 1950, 14, 429.

(30) Stepanov, B. I. Nature (London) 1946, 157, 808.
(31) Sheppard, N. In Hydrogen Bonding; Hadzi, D., Ed.; Pergamon Press: London, 1959; p 85

(32) Somorjai, R.; Hornig, D. F. J. Chem. Phys. 1962, 36, 1980

(33) Blink, R.; Hadzi, D. Mol. Phys. 1958, 1, 391.

(34) Pshenischnov, E. A.; Sokolov, N. D. Opt. Spectrosc. 1961, 11, 16.

(35) Janoschek, R.; Weidemann, E. G.; Zundel, G. Trans. Faraday Soc. 1973, 69, 505.

(36) Lohse, H.; Parlitz, B.; Patzelova, V. J. Phys. Chem. 1989, 93, 3677.

(37) Vorbeck, G.; Richter, M.: Fricke, R.; Parlitz, B.; Schreier, E.; Szulzewsky, K.; Zibrowius, B. In Catalysis and Adsorption by Zeolites; Ohlmann, G., Pfeifer, H., Fricke, R., Eds.; Elsevier: Amsterdam, 1991; p 631.

(38) Jacobs, W. P. J. H.; van Wolput, J. H. M. C.; van Santen, R. A. Chem. Phys. Lett. 1993, 210, 32.

(39) Jacobs, W. P. J. H.; van Wolput, J. H. M. C.; van Santen, R. A.; Jobic, H. Zeolites 1994, 14, 117.

(40) Flanigen, E. M. In Zeolite Chemistry and Catalysis; Rabo, J. A., Ed.; ACS Monograph 171; American Chemical Society: Washington DC, 1976; $p 93$.

(41) van Santen, R. A.; Vogel, D. L. Adv. Solid State Chem. 1989, I, 151

(42) Pimentel, G. C.; McClellan, A. L. The Hydrogen Bond; Reinold Publishing Corp.: New York, 1960.

(43) Baumann, J.; Beer, R.; Calzaferri, G.; Waldeck, B. J. Phys. Chem. $1989,93,2292$.

(44) This can be inferred also from an experimental finding by Odinokov et al ${ }^{26}$ that in series of closely related $\mathrm{X}-\mathrm{OH}-\mathrm{Y}$ complexes the "center of gravity" of the A + B + C band shifts to lower frequencies on strengthening the $\mathrm{H}$ bond. The "center of gravity" is defined $\mathrm{d}^{26}$ as the crossing point of the $v$ axis and the vertical line dividing the $\mathrm{A}+\mathrm{B}+\mathrm{C}$ area into two subareas with equal integral intensity. It should approximately correspond to the wavenumber of the maximum of the $v(\mathrm{OH}) \pm k v(\mathrm{OH}-\mathrm{Y})$ band in the absence of the resonance interactions generating the Evans windows. ${ }^{21,26}$

(45) Howard, J.; Lux, P. J.; Yarwood, J. Zeolites 1988, 8, 427.

(46) Fyfe, C. A.; Kennedy, G. T.; de Schutter, C. T.; Kokotailo, G. T. J. Chem. Soc., Chem. Commun. 1984, 541.

(47) The subtraction of spectra of the unloaded H-zeolites from spectra of the corresponding H/D-zeolites produces the "zero-intensity" line in the $1800-2000 \mathrm{~cm}^{-1}$ region, which shows the lattice 1880 and $2007 \mathrm{~cm}^{-1}$ bands of these zeolites to be independent of the $\mathrm{H} \rightarrow \mathrm{D}$ exchange.

(48) Mix, H.; Sauer, J.; Schroder, K.-P.; Merkel, A. Coll. Czech. Chem. Commun. 1988, 53, 2191.

JP941182K 